\title{
Indirect Treatment Comparison of Abatacept with Methotrexate Versus Other Biologic Agents for Active Rheumatoid Arthritis Despite Methotrexate Therapy in the United Kingdom
}

\author{
PATRICIA GUYOT, PETER C. TAYLOR, ROBIN CHRISTENSEN, LOUISA PERICLEOUS, PIETER DROST, \\ INDRA EIJGELSHOVEN, GERT BERGMAN, and MAXIMILIAN LEBMEIER
}

\begin{abstract}
Objective. To compare the efficacy of abatacept and alternative biologic disease-modifying antirheumatic drugs (DMARD) in patients with rheumatoid arthritis (RA) and an inadequate response to methotrexate (MTX) in the United Kingdom.

Methods. A systematic literature search identified 11 individual studies investigating the efficacy of abatacept, infliximab, adalimumab, etanercept, certolizumab pegol, and golimumab in adult patients with RA that did not respond to MTX. The clinical trials included in this analysis were similar in trial design, baseline patient characteristics, and background therapy (i.e., MTX). The key clinical endpoints of interest were the Health Assessment Questionnaire (HAQ) change from baseline (CFB) and the American College of Rheumatology (ACR) responses at 6 months (24-28 weeks). Results were analyzed using Bayesian network metaanalysis methods, and were expressed as differences in HAQ CFB and ACR20/50/70 relative risks, with $95 \%$ credible limits $(\mathrm{CrL})$.

Results. Analysis of HAQ CFB at 6 months showed that abatacept is more efficacious than placebo [mean difference in HAQ CFB: $-0.30(95 \% \mathrm{CrL}-0.42 ;-0.16)$ ] and comparable to all other biologic agents, in patients receiving MTX as background treatment. Abatacept is also expected to result in a higher proportion of ACR responders compared to placebo, with relative risks ranging from 1.90 (95\% CrL 1.24; 2.57) for ACR20 to 3.72 (95\% CrL 1.50; 10.52) for ACR70, and to result in comparable proportions of ACR responders as other biologic agents, at 6 months.

Conclusion. Abatacept is expected to result in improvement in functional status comparable to other recommended biologic agents in patients with RA who are unresponsive to MTX in the UK. (J Rheumatol First Release April 15 2012; doi:10.3899/jrheum.111345)
\end{abstract}

Key Indexing Terms:

RHEUMATOID ARTHRITIS

REVIEW LITERATURE AS TOPIC

$\begin{array}{lr}\text { THERAPEUTICS } & \text { ANTIRHEUMATIC AGENTS } \\ \text { METAANALYSIS AS TOPIC } & \text { GREAT BRITAIN }\end{array}$

From the Mapi Consultancy, Houten, The Netherlands; Kennedy Institute of Rheumatology, Nuffield Department of Orthopaedics, Rheumatology and Musculoskeletal Sciences, University of Oxford, Botnar Research Centre, Oxford, UK; Bristol-Myers Squibb Pharmaceuticals Ltd., Uxbridge, Middlesex, England, and Bristol-Myers Squibb International Corporation, Braine-l'Alleud, Belgium; and The Parker Institute, Musculoskeletal Statistics Unit, Copenhagen University Hospital, Copenhagen, Denmark.

Supported by Bristol-Myers Squibb.

P. Guyot, MSc, Mapi Consultancy; P.C. Taylor, PhD, FRCP, Kennedy Institute of Rheumatology, Nuffield Department of Orthopaedics,

Rheumatology and Musculoskeletal Sciences, University of Oxford, Botnar Research Centre; R. Christensen, PhD, Musculoskeletal Statistics Unit, Copenhagen University Hospital; L. Pericleous, PhD, Bristol-Myers Squibb Pharmaceuticals Ltd.; P. Drost, MSc, Bristol-Myers Squibb International; I. Eijgelshoven, BSc; G. Bergman, PhD, Mapi Consultancy; M. Lebmeier, PhD, Bristol-Myers Squibb Pharmaceuticals Ltd.

Address correspondence to Dr. M. Lebmeier, Bristol-Myers Squibb Pharmaceuticals Ltd., Uxbridge Business Park, Sanderson Road,

Uxbridge, Middlesex UB8 1DH, UK.

E-mail:maximilian.lebmeier@bms.com

Accepted for publication February 7, 2012.
The National Institute of Health and Clinical Excellence (NICE), in the United Kingdom, has recommended early use of disease-modifying antirheumatic drugs (DMARD) to reduce disease progression and longterm disability in patients with rheumatoid arthritis (RA) ${ }^{1}$. For patients with an insufficient response to treatment with methotrexate (MTX) and/or other conventional DMARD, NICE recommends adalimum$a b$, etanercept, infliximab, and certolizumab pegol. Most biologic agents are administered by subcutaneous injection; an exception is infliximab, which is administered by intravenous (IV) infusion. An IV infusion may have advantages for certain patient groups, such as those with significant comorbidities who would benefit from regular review at an infusion center, those who cannot self-inject, and those with compliance issues.

Abatacept is a biological DMARD and acts by selectively modulating an essential costimulatory pathway needed for $\mathrm{T}$ cell activation, thus inhibiting the inflammatory process at an

Personal non-commercial use only. The Journal of Rheumatology Copyright @ 2012 . All rights reserved. 
earlier stage than tumor necrosis factor- $\alpha(\mathrm{TNF}-\alpha)$ inhibitors $^{2}$. Like infliximab, abatacept is available through IV infusion. In May 2005, abatacept in combination with MTX received a UK marketing authorization in adult patients with RA who responded inadequately to previous TNF- $\alpha$ inhibitor therapy ${ }^{3}$. In addition, a license extension was approved for patients who responded inadequately to DMARD, including $\mathrm{MTX}^{4}$. The effectiveness of abatacept in this patient population has been demonstrated in a series of randomized controlled trials $(\mathrm{RCT})^{5,6,7,8,9}$. Trial data on the comparative efficacy of abatacept to alternative biologic agents are lacking and can be overcome by indirect treatment comparison methods ${ }^{10}$.

Our objective was to perform an indirect treatment comparison of recommended biologic agents in the United Kingdom in patients unresponsive to MTX, golimumab (in anticipation of its recommendation), and abatacept, based on a systematic review of the published clinical evidence by means of improving functional status as measured by the Health Assessment Questionnaire (HAQ) and the American College of Rheumatology (ACR) response rates. The HAQ score is often used as the key clinical driver in several cost-effectiveness analyses evolutions in RA, whereas the ACR response criteria have been recommended as key disease activity response measures by European League Against Rheumatism (EULAR)/ACR collaborative recommendations ${ }^{11}$.

\section{MATERIALS AND METHODS}

Systematic literature review. A systematic review was performed to identify those RCT that have investigated the efficacy of biologic DMARD licensed to treat RA when MTX is insufficient. Medline and Embase databases were searched simultaneously using Datastar. Further searches were done of the Cochrane Library, the technology appraisals for the United Kingdom, and reports of the ACR and EULAR conferences. Searches included a combination of free-text and Medical Subject Headings terms for "disease terms" with "drug names," and were limited to "human" RCT published in English between January 1980 and October 2010. The ACR and EULAR conferences were searched from 2008 to 2010. Full-text articles were assessed for inclusion by 2 reviewers according to the following selection criteria: (1) treatment combinations of MTX with abatacept, infliximab, etanercept, adalimumab, certolizumab, golimumab, or placebo in comparison with each other; (2) RA patients with an inadequate response or intolerance to previous treatment with at least 1 conventional DMARD (MTX, sulfasalazine, leflunomide, azathioprine, gold salts, or minocycline); and (3) clinical endpoints of HAQ change from baseline (CFB) at 6 months and the ACR response rates at 6 months.

The HAQ ${ }^{12,13}$ is a tool designed for patient self-assessment of physical functioning. For a clinically significant improvement, the measured difference should be at least 0.22 . In the abatacept studies, the minimum clinically relevant difference was defined as a change of $\geq 0.3$ units from the baseline value.

The ACR20/50/70 response criteria ${ }^{14}$ are defined by a $20 \% / 50 \% / 70 \%$ reduction in the number of swollen and tender joints, and a reduction of $20 \% / 50 \% / 70 \%$ in 3 of the following 5 measures: physician global assessment of disease, patient global assessment of disease, patient assessment of pain, C-reactive protein (CRP) or erythrocyte sedimentation rate, and degree of disability in HAQ score.

Data collection. For each selected study the details of design, selection criteria, study population characteristics, interventions, outcome measures, length of followup, and results were extracted. One researcher performed the data extraction, and another reviewed and validated the data extracted.
Network metaanalyses. The search strategy inclusion criteria were developed to be sure that no relevant study was missing, while the network metaanalyses criteria were chosen to ensure coherent analyses. Therefore, the inclusion criteria for the analyses were restricted as follows: (1) only recommended dosages licensed for treatment in the United Kingdom, and (2) only patients with RA who had an inadequate response or intolerance to MTX. The quantitative results of the different interventions from the studies identified were combined by Bayesian network metaanalyses techniques (also called indirect treatment comparison $)^{10}$. All analyses were performed using a noninformative prior distribution, and either a fixed effect or a random effects model was chosen, depending on the heterogeneity as assessed by the deviance information criteria ${ }^{10}$. Analyses were performed for the endpoints of HAQ CFB (continuous outcome) and ACR response criteria (dichotomous outcomes) using placebo (in combination with MTX) as the common comparator. The differences in mean HAQ CFB and estimates of relative risks (RR) for ACR 20/50/70, at 6 months, were presented along with their $95 \%$ credible limits $(\mathrm{CrL})$, for each biologic agent and placebo compared to abatacept. The results were adjusted to provide expected absolute mean $\mathrm{HAQ} \mathrm{CFB}$ and its $95 \% \mathrm{CrL}$, and expected absolute ACR 20/50/70 probability of response and its $95 \%$ $\mathrm{CrL}$, for abatacept, placebo, and the other biologic agents. For the relative efficacies as well as for the absolute responses, the point estimates reflect the most likely value for the measure considered, and the credible intervals reflect the range of true underlying effects with $95 \%$ probability.

For the HAQ CFB analyses, the SD was directly extracted from the publications if possible. When the SD was not reported, it was estimated based on other statistics that allow calculation or estimation of the SD (e.g., CI, SE, $t$ value, $p$ value, $f$ value). When no information about the uncertainty was available, the average of all the other SD explicitly reported was imputed to the missing SD, enabling integration of all the data available.

The feasibility of the network metaanalysis was evaluated by means of a qualitative assessment of the comparability of the studies in terms of study design, treatments evaluated, patient population, and quality of the network of studies. A base case, i.e., the broadest evidence base available and comparable in terms of effect modifiers characteristics, was then defined, as well as some scenario analyses that permit testing of the assumptions made in the base case. Analyses were performed with WinBUGS 1.4 statistical software.

\section{RESULTS}

Systematic review. The systematic literature review identified 21 documents: 17 publications, 2 Clinical Study Reports, 1 NICE submission, and 1 abstract, relevant for the indirect treatment comparison (Figure 1). The 21 documents included 11 individual studies for abatacept ( 3 trials $\left.^{5,6,7,8,9}\right)$, infliximab (2 trials ${ }^{6,15,16}$ ), adalimumab ( 2 trials ${ }^{17,18}$ ), etanercept ( 2 trials $\left.{ }^{19,20,21}\right)$, certolizumab pegol ( 2 trials $\left.^{23,24,25}\right)$, and golimum$\mathrm{ab}\left(1\right.$ trial $\left.^{26}\right)$. Each comparison was supported by at least 1 pivotal trial, but not all trials reported findings for the HAQ CFB and ACR response rates at 6 months. All 11 studies were randomized, double-blind, and placebo-controlled trials.

Comparability of study design and included patients. The included studies generally were of comparable design, but there were some notable differences. The adalimumab studies included early escape or rescue therapy at 16 weeks for nonACR20 responders (patients were allowed to receive rescue treatment with traditional DMARD in the DE019 trial and to roll over to an open-label continuation study with adalimum$a b$ in the ARMADA trial). The certolizumab pegol studies specifically withdrew patients who did not show an ACR20 response at Weeks 12 and $14(63 \%$ and $87 \%$ in the placebo arm and $21 \%$ and $30 \%$ in the treatment arm for RAPID and 
Search strategy:

* 1980 - Jan 2010: Datastar (Embase, Medline, Medline in progress), Cochrane RCT Library

* Jan 2010 - Oct 2010: Ovid (Embase, Medline, Medline in Progress), Cochrane RCT Library

Retrieved from: Datastar, Ovid and Cochrane RCT Library: 1744

* Other sources: BMS CSR, Conferences 2008 - 2010: ACR and EULAR and NICE/STA submission

Retrieved from: Other sources: 2 BMS CSR, 106 abstracts, 1 STA submission

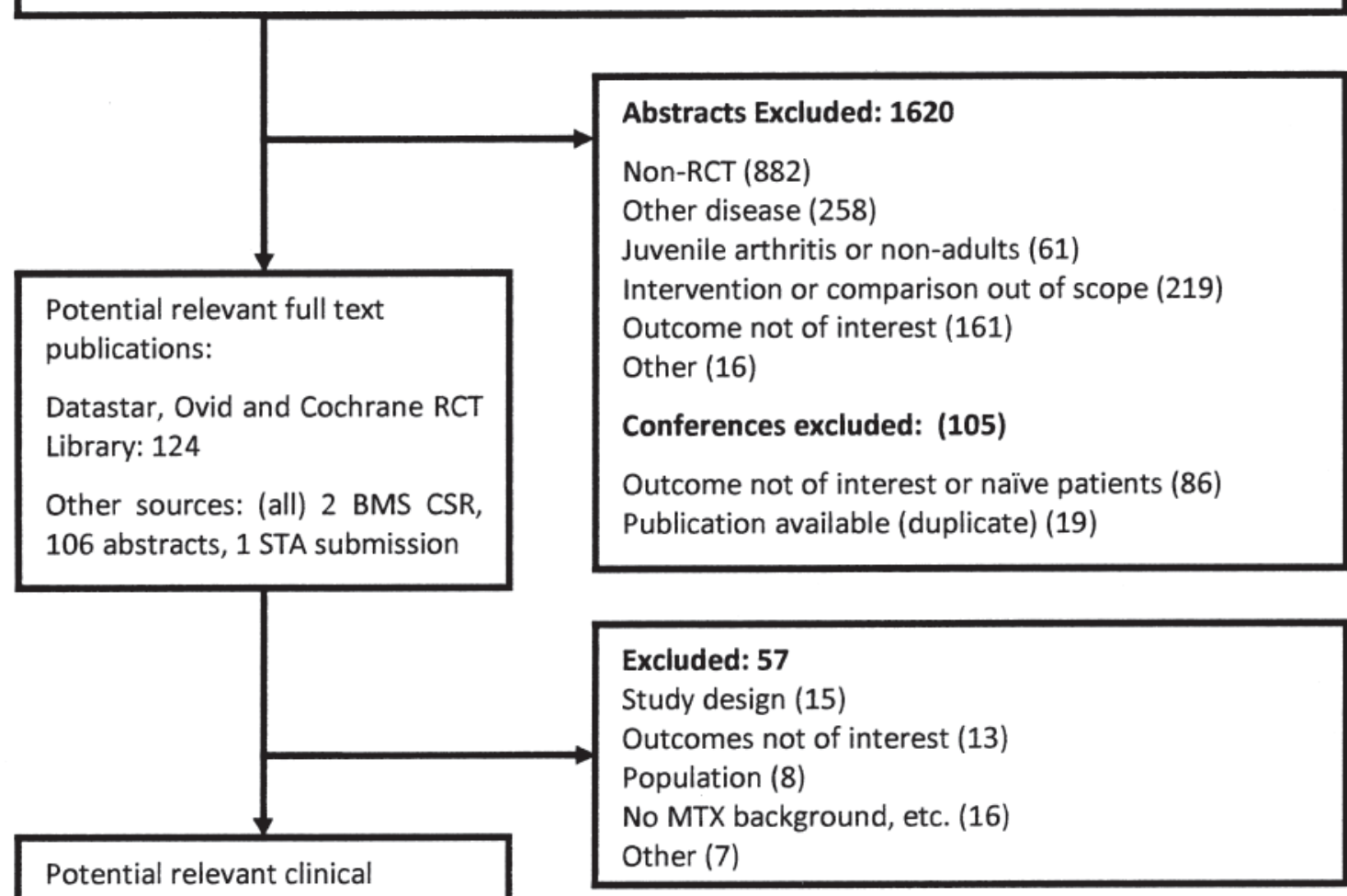

effectiveness documents

selected:

63 relevant clinical publications,

2 CSR and 1 STA submission

1 conference abstract

\section{Excluded for MTC: 46}

Open-label extension (11)

Outcome not of interest (15)

Other cDMARDS (5)

Naïve patients (6)

Non-relevant biologic (8)

Duplicate information (1)
Included for MTC 21 documents:

Abatacept (5 pub, 2 CSR), Adalimumab ( 2 pub), Certolizumab (3 pub) + (1 STA report), Etanercept (3 pub), Golimumab (1 pub) + (1 abstract) and Infliximab (3 pub)
Figure 1. Selection of included publications. RCT: randomized controlled trials; ACR: American College of Rheumatology; BMS: Bristol-Myers Squibb; CSR: clinical study report; EULAR:

European League Against Rheumatism; NICE: National Institute for Health and Clinical Excellence (UK); STA: single technology appraisal; MTX: methotrexate; DMARD: disease-modifying antirheumatic drug. 
RAPID II, respectively). The golimumab trial provided rescue therapy for patients who did not achieve at least $20 \%$ improvement in both tender joint count (TJC) and swollen joint count (SJC) by Week 16 (32\% of the patients in the placebo group switched to golumimab and $17 \%$ of the patients in the golimumab group switched to a higher dose of golimumab). The other studies, including the abatacept trials, did not report any escape or rescue therapy in their protocols. Another difference is that the TEMPO trial included patients who showed an inadequate response to DMARD rather than explicit inadequate response to MTX. In addition, patient eligibility criteria only required patients to have an SJC and TJC of $\geq 4$ in GO-FORWARD (golimumab), $\geq 6$ in Weinblatt, et $a l^{21}$ (etanercept) and ATTRACT (infliximab), and $\geq 6$ for SJC and $\geq 9$ for TJC in ARMADA and DE019 (adalimumab). These criteria are less stringent than those in other trials and may reflect a less advanced state of RA (for example, in the AIM trial, eligible patients had to have $\geq 10$ swollen joints and $\geq 12$ tender joints).

An overview of the baseline patient characteristics is provided in Table 1 . The studies were not completely homogeneous in terms of patient and disease duration characteristics. Some studies (GO-FORWARD ${ }^{25}$, RAPID I ${ }^{22,26}$, RAPID II ${ }^{24}$, and TEMPO ${ }^{19,20}$ ) reported shorter disease duration, with a mean of 4.5-6.8 years, while the other studies reported longer disease durations (with means 7.3-13 years). In terms of patient characteristics, the GO-FORWARD study included patients with an SJC of 11-13 compared with 17-23 for the other studies, and lower CRP levels (8-10 mg/l compared with $13-40 \mathrm{mg} / \mathrm{l}$ for the other studies).

All studies reported similar HAQ scores at baseline, except for the abatacept study by Kremer, et $a l^{7}$, which presented a

Table 1. Overview of characteristics of patients by treatment arm and trial. The treatment arms not used in the network metaanalysis do not appear; only treatment arms presenting the recommended dosages are reported.

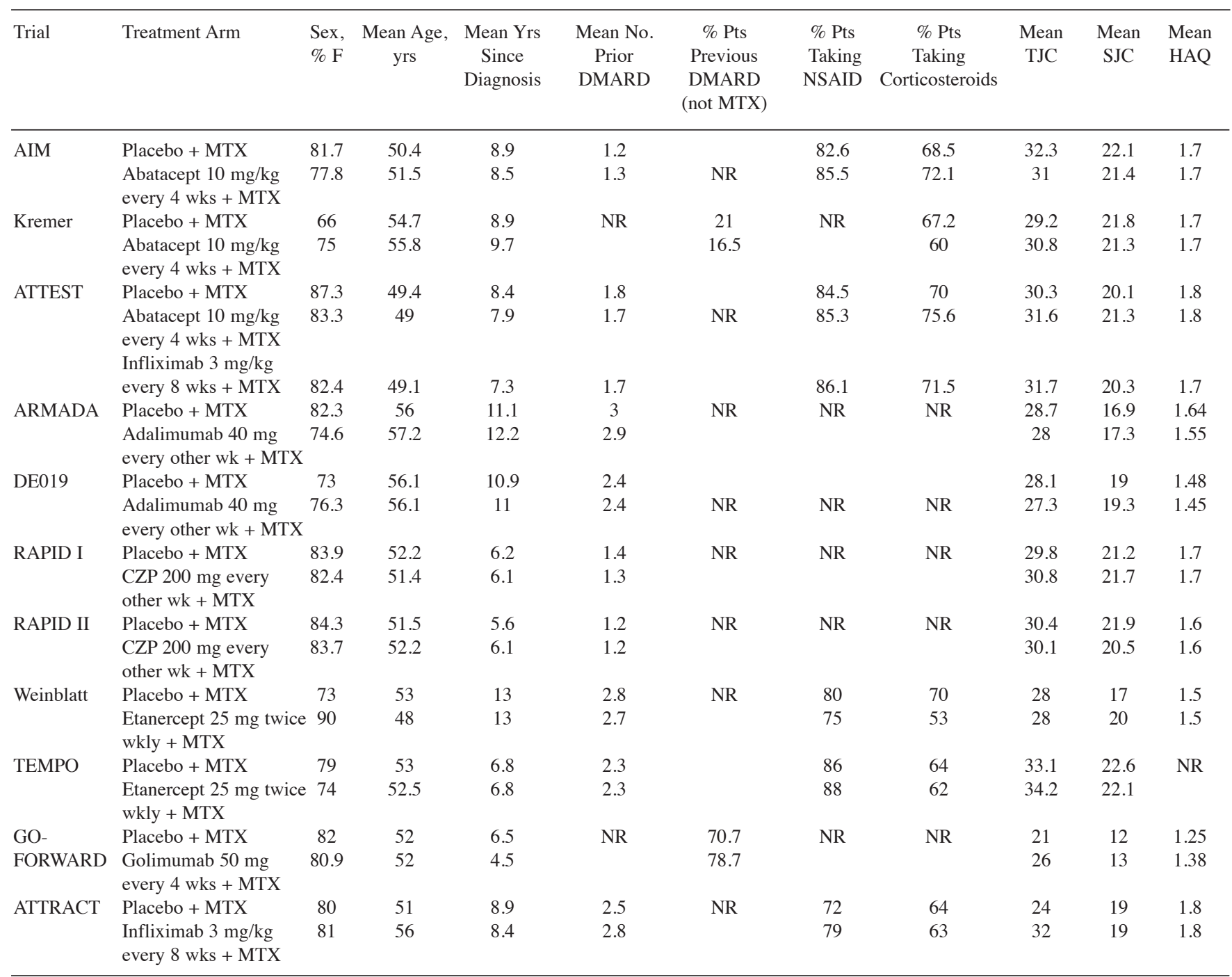

HAQ: Health Assessment Questionnaire; MTX: methotrexate; NSAID: nonsteroidal antiinflammatory drug; RF: rheumatoid factor; SJC: swollen joint count; TJC: tender joint count; NR: not reported. 
lower mean HAQ baseline value. This difference was likely to be due to the use of the modified HAQ instead of the traditional HAQ. Both instruments are strongly correlated, with a Pearson correlation coefficient of $0.88^{27}$, so the difference in the instruments is assumed to have no influence on the relative treatment effect.

These differences could explain potential differences in the observed relative treatment effects, and therefore lead to the use of random effects models to take heterogeneity into account across trials.

Network metaanalysis results. The relative difference between the HAQ CFB scores showed abatacept in combination with MTX to be more effective than placebo in combination with MTX in improving functional status (difference in HAQ CFB vs placebo: $-0.30,95 \% \mathrm{CrL}-0.42 ;-0.16)$. The expected absolute HAQ CFB for abatacept $(-0.57,95 \% \mathrm{CrL}-0.69$; $-0.43)$ was superior to placebo $(-0.27,95 \% \mathrm{CrL}-0.30$; -0.24 ), and comparable to the other biologics (expected mean between -0.46 and -0.65 ; Figure 2). Abatacept may be as efficacious as all other biological agents in patients receiving MTX as background therapy. The point estimates of the relative differences in mean HAQ CFB of abatacept versus other biological agents varied from -0.11 (vs infliximab) to 0.09 (vs certolizumab pegol; Figure 3).

ACR response criteria at 6 months. Abatacept was found to be more efficacious than placebo for each ACR response criterion (Figure 4). All biological agents evaluated are expected to result in comparable proportions of ACR20/50/70 responders, although the findings show that certolizumab pegol is expected to have a higher ACR20 response rate at 6 months than other biological agents. Abatacept appears to have a numerical benefit over etanercept (except for ACR70) and infliximab, but not over adalimumab, certolizumab pegol, and golimumab (Figure 5).
Sensitivity analyses. The TEMPO trial was included in the base case analysis as it was the pivotal trial for etanercept in this patient population. However, the TEMPO trial included a population that did not respond to DMARD and did not have recent MTX exposure or was MTX-naive, in distinction from the populations that had inadequate response to MTX and were recruited for the other trials. It also showed high observed response rates in the control group, which were substantially different from control responses in other studies. Therefore, the high response rates reported in both the test and control arms of the TEMPO study (Table 2) might be explained by the significant proportion of patients entering this trial who have not experienced MTX failure. Removing the TEMPO trial did not significantly affect the mean HAQ CFB at 6 months. Abatacept still showed comparable efficacy to the other biological treatments, including etanercept (difference in HAQ CFB vs etanercept at 6 months: $-0.03,95 \%$ $\mathrm{CrL}-0.25 ; 0.19$ ).

In the base case analysis, all randomized patients were included for the AIM trial, although patients included from 1 site were excluded from the efficacy analyses because of protocol violations. A sensitivity analysis excluding this site for the AIM results was evaluated and did not change the relative efficacy of abatacept to other biological agents (data not reported).

\section{DISCUSSION}

A systematic review of the literature and an indirect treatment comparison were performed to estimate the relative efficacy of abatacept compared with other relevant biological DMARD in the treatment of patients with RA with insufficient response to MTX in the United Kingdom. Indications are that abatacept will show a comparable efficacy in HAQ score and ACR response criteria to other routinely used biological agents in combination with MTX.

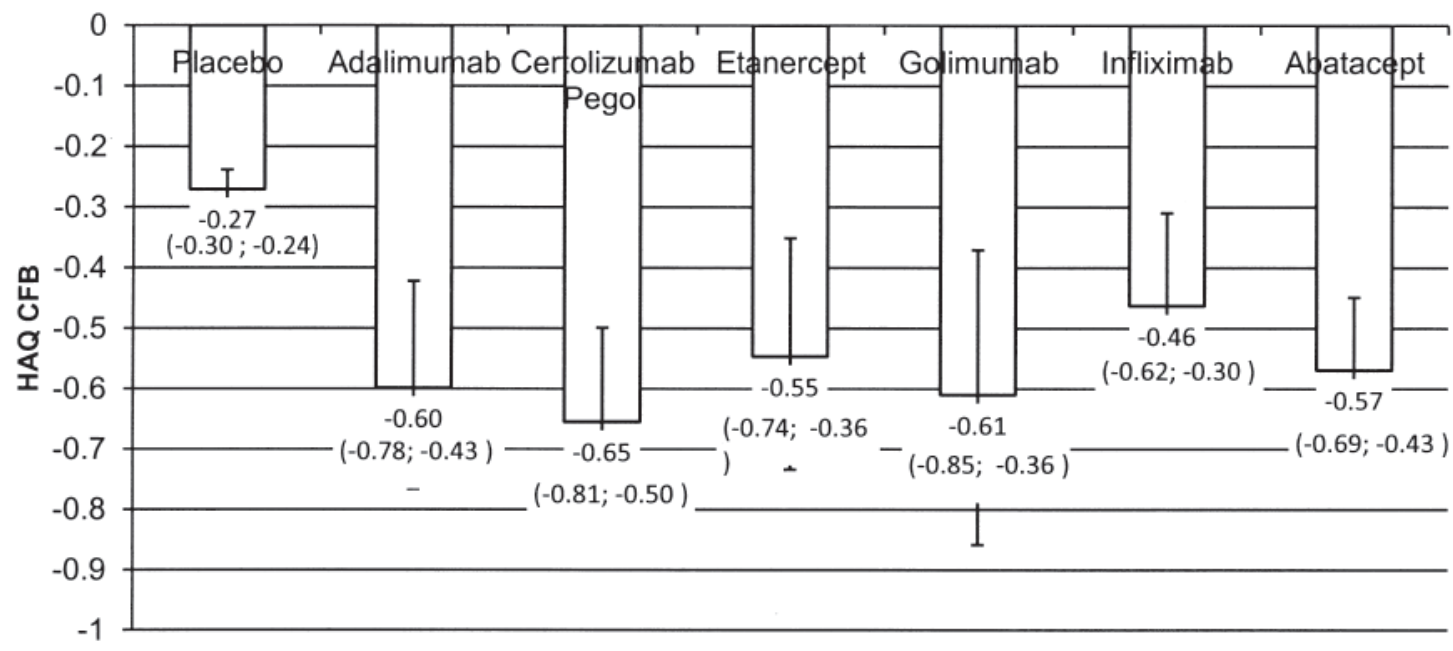

Figure 2. Expected absolute Health Assessment Questionnaire (HAQ) change from baseline (CFB), all treatments, at 6 months. Findings were based on a random effects model. Absolute CFB were calculated by adding the crude average placebo response to the treatment-specific CFB.

Personal non-commercial use only. The Journal of Rheumatology Copyright (C) 2012. All rights reserved. 


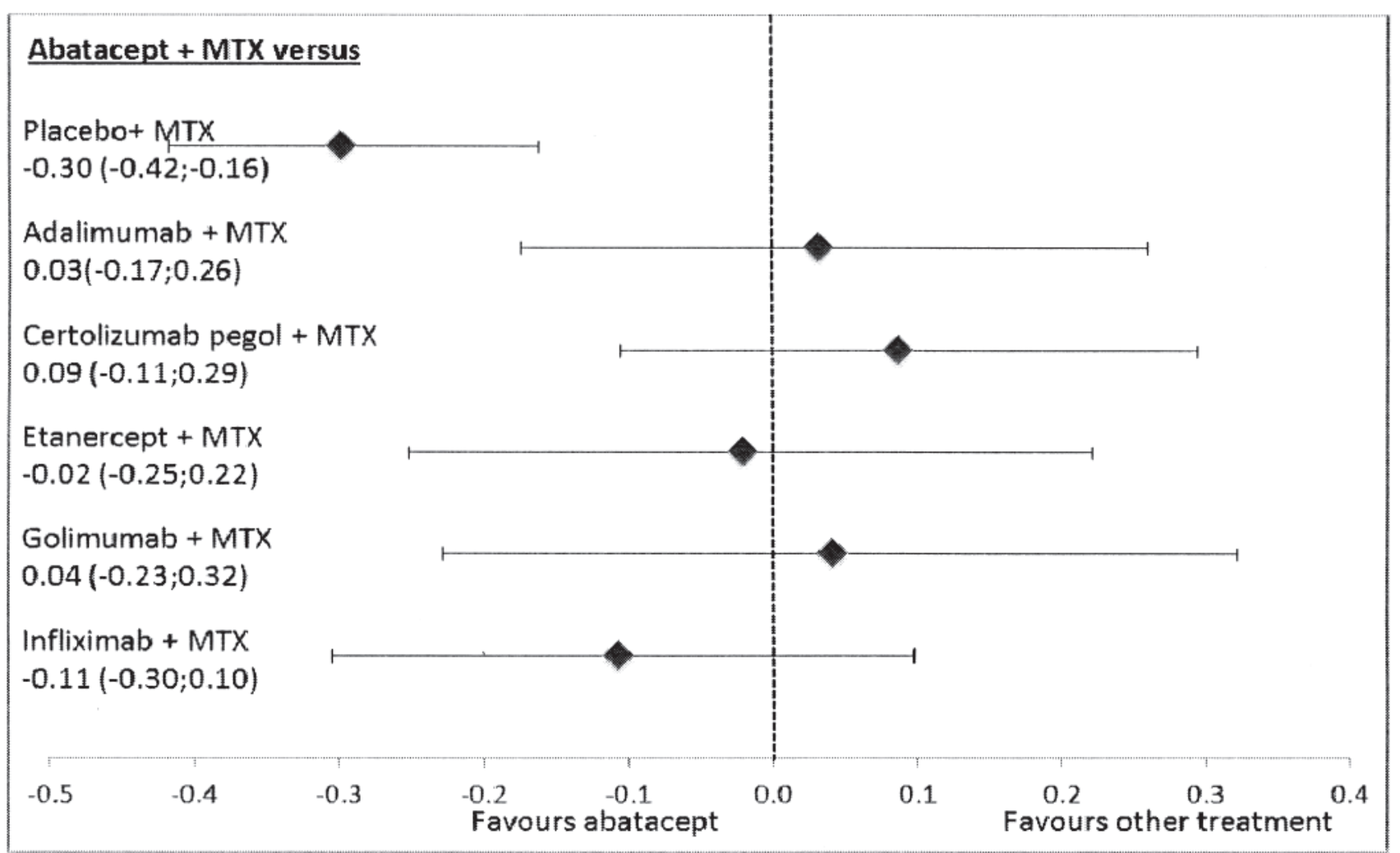

Figure 3. Relative Health Assessment Questionnaire (HAQ) change from baseline (CFB) abatacept compared to all other treatments at 6 months. Findings were based on a random effects model. MTX: methotrexate.

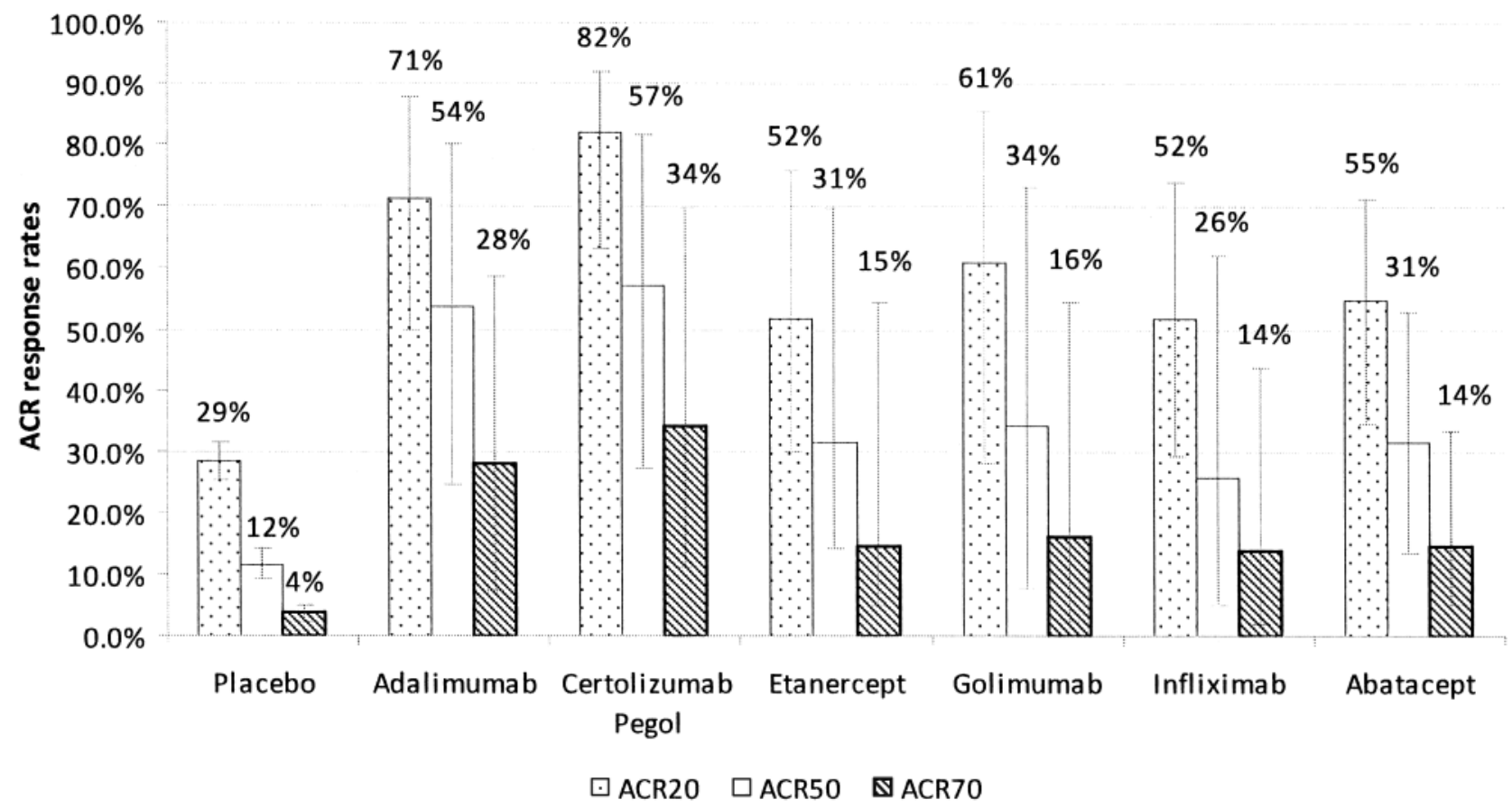

Figure 4. American College of Rheumatology (ACR) 20/50/70 response rates at 6 months. Findings were based on a random effects model. Absolute proportions were calculated by multiplying the crude average placebo response with the treatment-specific relative risk. 


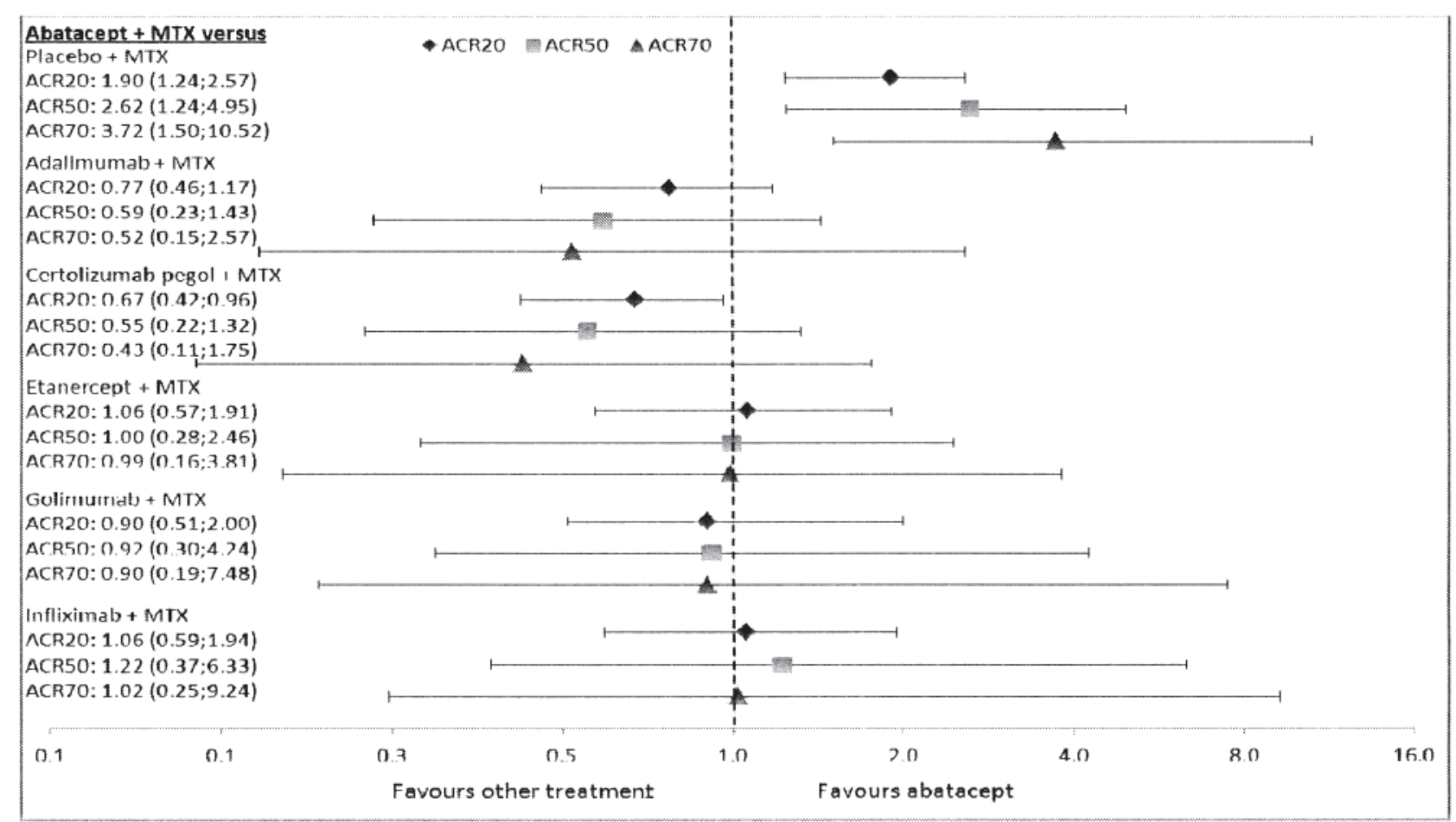

Figure 5. American College of Rheumatology (ACR) 20/50/70 response rates (relative risks): treatment effect relative to abatacept. Findings were based on a random effects model. MTX: methotrexate.

An indirect treatment comparison is credible only if the trial data used in the analyses are uniform. The similarity assumption could be violated by differences across the trials (i.e., clinical heterogeneity), which would introduce bias into the findings. Our study attempted to include only studies that were comparable across patient populations and study design. However, it should be noted that the patient population in the TEMPO trial included those with an inadequate response to any conventional DMARD and not specifically MTX, and etanercept is evaluated in only 2 trials: an older and relatively small study ${ }^{21}$ and the pivotal trial for etanercept (TEMPO). We decided to include the TEMPO trial in the base case analysis because of its pivotal position and to evaluate the potential effect of its exclusion in a scenario analysis. We found that its exclusion did not change the interpretation of the findings.

Other limitations in comparability of study and patient characteristics were observed with the golimumab and certolizumab pegol trials. For golimumab, the main publication 25 reported median and interquartile range data instead of mean and $\mathrm{SD}$, and this may have challenged the assumed normality of the data. Our study also included patients presenting with lower SJC, a lower CRP level, and shorter disease duration than most of the other studies. Certolizumab pegol $22,23,24,26$ and etanercept $\mathrm{t}^{20,28}$ also had studies reporting shorter disease duration. The difference in design of the certolizumab pegol studies, i.e., that patients were withdrawn if they did not show ACR responses at 12 and 14 weeks, may partly explain the high mean HAQ CFB after adjustment estimate for cer- tolizumab pegol. Because of the limited number of studies, the effect associated with the golimumab and certolizumab pegol studies $^{22,23,24}$ was not explored in either metaregression or scenario analyses. Excluding 1 of these studies would have removed at least 1 treatment from the analysis, without providing any additional information on the potential presence of bias. The only effect would have been to leave the decision makers with no estimate at all for the comparison of the removed biological agents with the other comparators.

To take into account the heterogeneity across trials and try to reduce the possible confounding bias, random effect models have been used. Aside from comparability issues, the direct evidence from trials could not be supported by indirect evidence (the exception being the ATTEST ${ }^{6}$ trial reporting both the relative effects vs placebo for abatacept and infliximab). The introduction of bias in this indirect treatment comparison could be neither fully excluded nor fully established. However, if the analysis is indeed biased, there is no evidence that a nonbiased indirect comparison would lead to a different conclusion. The approach taken is conservative because if it did indeed lead to a different conclusion, one would hypothesize a direction of bias in favor of abatacept (in the abatacept trials, the mean disease duration was higher and no rescue route was proposed). The analysis results presented here can be seen as the best estimates for the problems considered, given the data at hand, but would surely benefit from the addition of new data based on RCT with the same scope.

Other network metaanalyses have been published on bioPersonal non-commercial use only. The Journal of Rheumatology Copyright @ 2012 . All rights reserved. 
Table 2. Reported data for Health Assessment Questionnaire (HAQ) change from baseline (CFB) and American College of Rheumatology (ACR) 20/50/70 responses at 6 months.

\begin{tabular}{|c|c|c|c|c|c|}
\hline Trial & $\mathrm{N}$ & $\begin{array}{l}\text { Mean HAQ } \\
\text { CFB (SD) }\end{array}$ & $\begin{array}{c}\text { ACR20 } \\
\text { Responses }\end{array}$ & $\begin{array}{c}\text { ACR50 } \\
\text { Responses }\end{array}$ & $\begin{array}{c}\text { ACR70 } \\
\text { Responses }\end{array}$ \\
\hline \multicolumn{6}{|l|}{ Placebo + MTX } \\
\hline AIM & 219 & $-0.40(0.59)$ & 87 & 37 & 14 \\
\hline Kremer 2005, Kremer 2003 & 119 & $-0.14(0.49 *)$ & 42 & 14 & 2 \\
\hline ATTEST & 110 & $-0.29(0.22)$ & 46 & 22 & 10 \\
\hline ARMADA & 62 & $-0.27(0.57)$ & 9 & 5 & 3 \\
\hline DE019 & 200 & $-0.24(0.52)$ & 59 & 19 & 5 \\
\hline RAPID I & 199 & $-0.17(0.56)$ & 27 & 15 & 6 \\
\hline RAPID II & 127 & $-0.14(0.45)$ & 11 & 4 & 1 \\
\hline Weinblatt & 30 & $-0.40(0.49 *)$ & 8 & 1 & 0 \\
\hline TEMPO & 228 & $-0.63(1.08 *)$ & 167 & 92 & 34 \\
\hline GO-FORWARD & 133 & $-0.13(0.58)$ & 37 & 18 & 7 \\
\hline ATTRACT & 88 & $-0.19(0.49 *)$ & 18 & & \\
\hline \multicolumn{6}{|l|}{ Abatacept + MTX } \\
\hline AIM & 433 & $-0.59(0.62)$ & 294 & 173 & 86 \\
\hline Kremer 2005, Kremer 2003 & 115 & $-0.42(0.49 *)$ & 69 & 42 & 19 \\
\hline ATTEST & 156 & $-0.68(0.22)$ & 104 & 63 & 32 \\
\hline \multicolumn{6}{|l|}{ Adalimumab + MTX } \\
\hline ARMADA & 67 & $-0.62(0.63)$ & 45 & 37 & 18 \\
\hline DE019 & 207 & $-0.56(0.52)$ & 131 & 81 & 43 \\
\hline \multicolumn{6}{|l|}{ Certolizumab + MTX } \\
\hline RAPID I & 393 & $-0.58(0.59)$ & 231 & 146 & 84 \\
\hline RAPID II & 246 & $-0.50(0.47)$ & 141 & 80 & 39 \\
\hline \multicolumn{6}{|l|}{ Etanercept + MTX } \\
\hline Weinblatt 1999 & 59 & $-0.70(0.49 *)$ & 42 & 23 & 9 \\
\hline TEMPO & 231 & $-0.89\left(1.08^{*}\right)$ & 188 & 136 & 82 \\
\hline \multicolumn{6}{|l|}{ Golimumab + MTX } \\
\hline GO-FORWARD & 89 & $-0.47(0.55)$ & 53 & 33 & 18 \\
\hline \multicolumn{6}{|l|}{ Infliximab + MTX } \\
\hline ATTEST & 165 & $-0.53(0.29)$ & 98 & 61 & 40 \\
\hline ATTRACT & 86 & $-0.31\left(0.49^{*}\right)$ & 42 & & \\
\hline
\end{tabular}

* SD was estimated. MTX: methotrexate.

logical agents for patients with RA, such as the study from the Cochrane collaboration ${ }^{29}$. Our analysis was, however, different in terms of scope, justifying the need for a new analysis. We can cite other differences: the addition of certolizumab and golimumab treatments, the exclusion of anakinra and rituximab treatments, the criteria for patients who did not have an adequate response to MTX, or the combination with MTX (excluding biological agents as single therapy or in combination with other DMARD). Our study had a narrower scope; therefore, we expected less heterogeneity between the studies included and more reliable results for our specific population of interest. The numerical results were, as expected, somehow different from the Cochrane results, but the overall conclusion agreed: abatacept, adalimumab, etanercept, and infliximab showed comparable short-term efficacy in patients with RA.

Currently it is not possible to predict, on an individual basis, which patient will respond to a particular therapy - a significant unmet need that is the goal of much research. While there is still an absence of reliable biomarkers on which to base individual treatment decisions, it is important that patients have access to the full range of biological therapeutics with proven efficacy. This indirect treatment comparison strongly suggests that abatacept in combination with MTX is superior to placebo plus MTX, and also comparable to other biologic DMARD for the short-term reduction in disability and ACR response rates of RA for patients with active disease despite previous treatment with MTX. As shown in our network metaanalyses and the ATTEST trial ${ }^{6}$, abatacept is expected to be as efficacious as infliximab, the only other biologic delivered by IV administration while offering another working mechanism. This could especially be of interest for patients who are potentially noncompliant and patients who require close monitoring at an infusion center. In addition, a network metaanalysis from the Cochrane collaboration on the safety of the biologic agents $^{30}$ stated that abatacept was associated with a significantly lower risk of serious adverse events than certolizumab pegol, etanercept, and infliximab, and was associated with a significantly lower risk of serious infections than certolizumab pegol and infliximab. Therefore, based on its unique mechanism of action, efficacy, and clinical trial safety profile ${ }^{5,6,7,8,9}$, abatacept appears to be a suitable alternative to currently licensed biologic DMARD, in particular infliximab. 


\section{REFERENCES}

1. National Institute for Health and Clinical Excellence. NICE clinical guideline CG79: Rheumatoid arthritis: the management of rheumatoid arthritis in adults. [Internet. Accessed February 24, 2012.] Available from: http://guidance.nice.org.uk/CG79

2. Vincenti F, Luggen M. T cell costimulation: A rational target in the therapeutic armamentarium for autoimmune diseases and transplantation. Annu Rev Med 2007;58:347-58.

3. National Institute for Health and Clinical Excellence. Final scope for the appraisal of abatacept for the treatment of rheumatoid arthritis after the failure of conventional disease modifying anti-rheumatic drugs. November 2010. [Internet. Accessed March 5, 2012.] Available from: http://www.nice.org.uk/nicemedia/live/13137/51630/51630.pdf

4. Summary of product characteristics for Orencia. 2010. [Internet. Accessed February 24, 2012.] Available from: http://www.ema.europa.eu/docs/en_GB/document_library/ EPAR_-_Product_Information/human/000701/WC500048935.pdf

5. Russell AS, Wallenstein GV, Li T, Martin MC, Maclean R, Blaisdell $\mathrm{B}$, et al. Abatacept improves both the physical and mental health of patients with rheumatoid arthritis who have inadequate response to methotrexate treatment. Ann Rheum Dis 2007:66:189-94.

6. Schiff M, Keiserman M, Codding C, Songcharoen S, Berman A, Nayiager S, et al. Efficacy and safety of abatacept or infliximab vs placebo in ATTEST: A phase III, multi-centre, randomised, double-blind, placebo-controlled study in patients with rheumatoid arthritis and an inadequate response to methotrexate. Ann Rheum Dis 2008;67:1096-103.

7. Kremer J, Dougados M, Emery P, Durez P, Sibilia J, Shergy W, et al. Treatment of rheumatoid arthritis with the selective costimulation modulator abatacept: Twelve-month results of a phase IIb, double-blind, randomized, placebo-controlled trial. Arthritis Rheum 2005;52:2263-71.

8. Kremer J, Westhovens R, Leon M, Di G, Alten R, Steinfeld S, et al Treatment of rheumatoid arthritis by selective inhibition of T-cell activation with fusion protein CTLA4Ig. N Engl J Med 2003;349:1907-15.

9. Kremer JM, Genant HK, Moreland LW, Russell AS, Emery P, Abud-Mendoza C, et al. Effects of abatacept in patients with methotrexate-resistant active rheumatoid arthritis: A randomized trial Ann Intern Med 2006;144:865-76.

10. Jansen JP, Crawford B, Bergman G, Stam W. Bayesian meta-analysis of multiple treatment comparisons: An introduction to mixed treatment comparisons. Value Health 2008;11:956-64.

11. Aletaha D, Landewe R, Karonitsch T, Bathon J, Boers M, Bombardier $\mathrm{C}$, et al. Reporting disease activity in clinical trials of patients with rheumatoid arthritis: EULAR/ACR collaborative recommendations. Ann Rheum Dis 2008;67:1360-4.

12. Fries JF, Spitz P, Kraines RG, Holman HR. Measurement of patient outcome in arthritis. Arthritis Rheum 1980;23:137-45.

13. Ramey DR, Raynauld JP, Fries JF. The Health Assessment Questionnaire 1992: Status and review. Arthritis Care Res 1992;5:119-29.

14. American College of Rheumatology Subcommittee on Rheumatoid Arthritis Guidelines. Guidelines for the management of rheumatoid arthritis: 2002 Update. Arthritis Rheum 2002;46:328-46.

15. Lipsky PE, van der Heijde DM, St. Clair EW, Furst DE, Breedveld F, Kalden JR, et al; Anti-Tumor Necrosis Factor Trial in Rheumatoid Arthritis with Concomitant Therapy Study Group. Infliximab and methotrexate in the treatment of rheumatoid arthritis. N Engl J Med 2000;343:1594-602.

16. Maini R, St. Clair EW, Breedveld F, Furst D, Kalden J, Weisman M, et al. Infliximab chimeric anti-tumour necrosis factor alpha monoclonal antibody versus placebo in rheumatoid arthritis patients receiving concomitant methotrexate: A randomised phase III trial ATTRACT Study Group. Lancet 1999;354:1932-9.

17. Keystone E, Kavanaugh A, Sharp J, Tannenbaum H, Hua Y, Teoh L, et al. Radiographic, clinical, and functional outcomes of treatment with adalimumab (a human anti-tumor necrosis factor monoclonal antibody) in patients with active rheumatoid arthritis receiving concomitant methotrexate therapy: A randomized, placebo-controlled, 52-week trial. Arthritis Rheum 2004;50:1400-11.

18. Weinblatt M, Keystone E, Furst D, Moreland L, Weisman M, Birbara $\mathrm{C}$, et al. Adalimumab, a fully human anti-tumor necrosis factor alpha monoclonal antibody, for the treatment of rheumatoid arthritis in patients taking concomitant methotrexate: The ARMADA trial. Arthritis Rheum 2003;48:35-45.

19. Klareskog L, van der Heijde D, de Jager JP, Gough A, Kalden $\mathrm{J}$, Malaise M, et al; TEMPO (Trial of Etanercept and Methotrexate with Radiographic Patient Outcomes) study investigators. Therapeutic effect of the combination of etanercept and methotrexate compared with each treatment alone in patients with rheumatoid arthritis: Double-blind randomised controlled trial. Lancet 2004;363:675-81.

20. van der Heijde DM, Klareskog L, Singh A, Tornero J, Melo G, Codreanu C, et al. Patient reported outcomes in a trial of combination therapy with etanercept and methotrexate for rheumatoid arthritis: The TEMPO trial. Ann Rheum Dis 2006;65:328-34.

21. Weinblatt ME, Kremer JM, Bankhurst AD, Bulpitt KJ, Fleischmann RM, Fox RI, et al. A trial of etanercept, a recombinant tumor necrosis factor receptor:Fc fusion protein, in patients with rheumatoid arthritis receiving methotrexate. N Engl J Med 1999;340:253-9.

22. Keystone E, Heijde D, Mason D Jr, Landewé R, Vollenhoven RV, Combe $\mathrm{B}$, et al. Certolizumab pegol plus methotrexate is significantly more effective than placebo plus methotrexate in active rheumatoid arthritis: Findings of a fifty-two-week, phase III, multicenter, randomized, double-blind, placebo-controlled, parallel-group study. Arthritis Rheum 2008;58:3319-29.

23. Certolizumab pegol $\left(\mathrm{Cimzia}^{\circledR}\right)$ for the treatment of rheumatoid arthritis. Single technology appraisal (STA) manufacturer submission to NICE. 2009. [Internet. Accessed March 1, 2012.] Available from: http://www.nice.org.uk/nicemedia/live/11903/47141/47141.pdf

24. Smolen J, Landewé RB, Mease P, Brzezicki J, Mason D, Luijtens K, et al. Efficacy and safety of certolizumab pegol plus methotrexate in active rheumatoid arthritis: The RAPID 2 study. A randomised controlled trial. Ann Rheum Dis 2009;68:797-804.

25. Strand V, Mease P, Burmester GR, Nikai E, Coteur G, van Vollenhoven R, et al. Rapid and sustained improvements in health-related quality of life, fatigue, and other patient-reported outcomes in rheumatoid arthritis patients treated with certolizumab pegol plus methotrexate over 1 year: Results from the RAPID 1 randomized controlled trial. Arthritis Res Ther 2009;11:R170.

26. Keystone EC, Genovese MC, Klareskog L, Hsia EC, Hall ST, Miranda PC, et al; GO-FORWARD Study. Golimumab, a human antibody to tumour necrosis factor alpha given by monthly subcutaneous injections, in active rheumatoid arthritis despite methotrexate therapy: The GO-FORWARD Study. Ann Rheum Dis 2009;68:789-96.

27. Uhlig T, Haavardsholm EA, Kvien TK. Comparison of the Health Assessment Questionnaire (HAQ) and the modified HAQ (MHAQ) in patients with rheumatoid arthritis. Rheumatology 2006;45:454-8.

28. Singh JA, Christensen R, Wells GA, Suarez-Almazor ME, Buchbinder R, Lopez-Olivo MA, et al. Biologics for rheumatoid arthritis: An overview of Cochrane reviews. Cochrane Database Syst Rev 2009; 4:CD007848.

29. Singh JA, Wells GA, Christensen R, Tanjong Ghogomu E, Maxwell L, Macdonald JK, et al. Adverse effects of biologics: A network meta-analysis and Cochrane overview. Cochrane Database Syst Rev 2011;2:CD008794 